\title{
The Impact of Trust in Technology on the Appraisal of Technostress Creators in a Work-Related Context
}

\author{
Julia Theresia Zielonka \\ Johannes Gutenberg-Universität Mainz \\ julia.zielonka@uni-mainz.de
}

\begin{abstract}
Research in technostress examines how and why the use of information and communication technologies causes individuals to experience an imbalance between demands and the ability to meet them. In this paper, the impact of system-like trust and human-like trust on the appraisal of technostress creators in a work-related setting is examined. In order to test the propositions, data on trust, technostress creators, the perception of distress and eustress, and job satisfaction were collected in a web-based survey from 210 employees. Structural equation modeling was performed for data analysis. The results confirm that both, system-like trust and human-like trust, significantly affect the appraisal of technostress creators. In particular, the higher the trust in technology is, the less harmful technostress creators are perceived, which positively impacts job satisfaction.
\end{abstract}

\section{Introduction}

Information and communication technologies (ICT) have become ubiquitous in our lives. Whereas people in their private lives are still free to choose which ICT they want to adopt and to what extent, employees usually do not have the choice of ICT adoption, may it be due to explicit job requirements (e.g. usage of a specific software to meet accounting standards) or due to implicit norms at work (e.g. use of a digital calendar to make appointments) $[7,72]$. ICT in the professional environment are intended to support us at work and improve our performance. Thanks to ICT, we have rapid and easy access to information and can easily stay connected with whoever we want around the globe. In fact, ICT can disregard time or space boundaries and can make our professional and private lives easier, more efficient and more enjoyable. However, as soon as the first computers were used by professionals in order to support and increase their performance, negative aspects obviously emerged, too, such as the inability to effectively use offered technological resources or the general resistance to use ICT resulting in the perception of stress by the users [3]. These phenomena opened up a new area of interdisciplinary research in the field of psychology and information systems (IS) research [66]. Brod [5] soon named "the inability to adapt or cope with new computer technologies in a healthy manner" technostress. Nowadays, the definition of technostress in the area of information systems research has broadened to the feeling of stress which users experience due to the usage of ICT $[66,68]$. Stress is an adaptive response to stressors which are factors evoking feelings of distress inside an organism [19, 29, $34,35]$. With regard to technostress, ICT represent the stressors affecting individuals' well-being leading to negative outcomes such as feelings of hassle, helplessness, anxiety, resistance, technophobia and mental fatigue $[10,40,61,63,74]$. In addition, technostress not only influences an individual's psychological health but also its physical one with symptoms like headache, muscle cramps, insomnia, and joint aches [13, 22, 64].

As the negative psychological and physiological symptoms may result in job dissatisfaction, lower performance and productivity, decreased commitment, or burnout [1, 52, 68], scholars want to find solutions for preventing technostress. Therefore, they investigate the nature of technostress with its causes and consequences [17, 21]. There are plenty of studies examining the sources of technostress [22, 52, 66], which suggest to level the exposure to ICT to find a healthy balance while using modern technologies [15].

Scholars identified five major technology characteristics, which are found to be stressors leading to the perception of stress in terms of strain: technooverload, techno-insecurity, techno-invasion, technouncertainty, and techno-complexity [52, 68].

However, empirical evidence exists that the exposure to the same level of technostressors results in different levels of stress perceptions between individuals [49, 61]. Therefore, it has become of 
interest to find and investigate the factors influencing these stress mechanisms, which are decisive for individual stress perceptions in association with technology use. One approach deals with individuals' coping strategies to decrease technostress [47, 59]. However, coping is only necessary when technostress already occurs and exerts its negative effects on the users.

Effective strategies tackling the effects of technostress need to focus on the part before technostress evolves in the individual. Recent studies have taken this approach into account by examining possible moderators influencing the stressor-outcome relationship such as technology competence or technology self-efficacy [22, 59, 61, 67]. There are also studies looking at the relationship between certain personality traits and perceived technostress [28, 32, $38,49,58,61]$.

However, there still is a lack of research combining technostress perception and trust in technology. Trust is a concept which has been widely investigated and introduced for the explanation of technology acceptance and usage behavior [31, 44, 48]. Studies prove that trust in technology increases acceptance of technology and the intention to use technology [70, 71]. Since technology acceptance impacts the technostress process [76], it is derived that trust in technology also needs to be paid attention to when looking at technostress.

In this article, a novel perspective is introduced by arguing that perceived technostress depends on the individual's trust in technology. In contrast to current literature explaining the level of perceived technostress based on individuals' personality characteristics or innate technology competence, trust is not stable over time. Trust in technology can be changed and established towards the desired outcome [27]. This malleability of trust in technology raises the interest in looking closer at the impact of trust on perceived technostress. If the level of perceived technostress depends on the individual's trust, then technostress can be regulated by organizational measures of building trust in the technology to use at work.

Consequently, the goal of this paper is to theoretically develop and empirically study the impact of trust on the technostress process and its outcomes in terms of job satisfaction. In particular, the impact of trust on the appraisal of the major technostress creators, namely techno-overload, techno-insecurity, techno-invasion, techno-uncertainty, and technocomplexity is examined in a work-related context.

The proposed research model is tested with a total of 210 employees participating in an online survey, in which they were asked about their experiences with the technology software Microsoft Teams. Since the outbreak of the Covid19-pandemic the use of Microsoft Teams has increased immensely. Many companies around the world have rolled out Microsoft Teams to allow their employees to work from home and still be as connected as possible to the team. For many employees, the requirement to use Microsoft Teams for daily work was new. Especially in such situations, people tend to experience technostress [1, 6]. Accordingly, it is interesting to find out what role trust in the new software plays in the perception of stress. In addition, both system-like trust and humanlike trust was measured in order to capture the full picture of trust in Microsoft Teams because this software includes both system-like attributes and human-like attributes.

The results show that there is a significant effect of trust on the appraisal of technostress creators. In particular, trust in technology significantly reduces the perception of technostress creators, which in turn impact the perception of distress and eustress respectively. These findings advance technostress research by uncovering the potential of trust to regulate technostress.

The paper is structured as follows: The next sections highlight relevant research in the fields of technostress and trust in technology. Based on this theoretical background, the research model is developed which proposes that trust in technology affects the appraisal of technostress creators, which in turn affect the perception of stress and, therefore, influences job satisfaction. Thereafter, the methodology and the used items are described. Structural equation modeling is performed for data analysis and the results are presented and discussed. The paper ends with concluding remarks and avenues for future research.

\section{Theoretical background}

\subsection{The transactional (techno-) stress model}

According to the Transactional Theory of Stress, the perception of stress is an ongoing process of adaption based on transactions between the individual and his/her environment [19, 35]. This psychological perspective of stress perception acknowledges that external events do not directly lead to stress reactions but rather are negotiated within the individual $[36,57]$.

When external forces such as situations and demands affect impinge on the individual, the individual needs to appraise these forces as stressors (Figure 1). The individual can classify these environmental demands as threat or as challenge. Depending on the classification, the individual 
evaluates its possible coping responses to the stressors in the form of a secondary appraisal. This results in affect or actions leading to outcomes [19, 35, 36]. Key elements of this model are the cognitive appraisals, which are used to explain the different perceptions and levels of stress. It is on the individual to evaluate and decide if environmental conditions such as technologies are perceived as negative or positive and if the individual has the necessary effective coping strategies in order to respond to the stressor successfully. Although most of stress research is concerned about the adverse and detrimental effects of stressors and stress, there is also a positive side of stress, namely eustress $[8,53,56]$. While distress refers to appraising stressors as hindrances or threats, which leads to negative psychological and physiological outcomes [22], eustress refers to appraising stressors as challenges, which is linked to positive and affirmative outcomes by tackling successfully the challenges. Affirmative outcomes are known to be satisfaction, learning, improved performance and productivity $[8,9$, $50,75]$. It is important to note that the perception of challenge and hindrance, and therefore, also the perception of distress and eustress are not mutually exclusive but may rather coexist $[18,42]$.

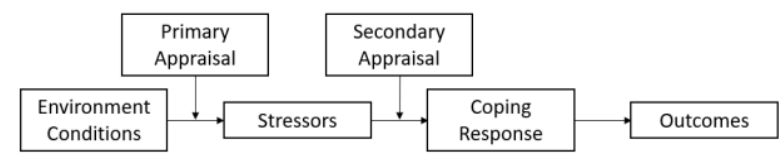

\section{Figure 1. Transactional Stress Model (adapted from [35])}

Stress in association with the usage of technology is referred to as technostress [5]. The concept of technostress addresses contexts in which stress processes are initiated by the use of technology [52, 66]. In our study, Microsoft Teams is the software technology, which can exceed the individual's resources or capabilities. The more the individual appraises the technology as threat, the higher is the perception of distress [67]. Literature predominantly views technology as a threat with its negative outcomes [66]. The five major technostressors, or technostress creators, are techno-overload, technoinvasion, techno-uncertainty, techno-complexity, and techno-insecurity $[2,15,40,60,68]$. Techno-overload refers to demands when the use of technology requires employees to work more or faster. Techno-invasion denotes the circumstances when technology enables constant reachability and the employee feels constantly connected to work through the use of technology. Techno-uncertainty is associated with the continuous changes in technology, which requires employees to always update their knowledge, otherwise they would be outdated. Techno-complexity relates to the effort and time employees need to invest in order to learn and understand new technology. Complex technology can be found to be intimidating and, therefore, leads to stress. Techno-insecurity refers to the threat of employees about losing their jobs to more knowledgeable people regarding technology use [52, 68]. In this study, all of these technostressors are aggregated and subsumed under the term technostress creators [61].

\subsection{Trust in technology}

The concept of trust has gained prominent attention in information systems research by being accounted for in various studies around the Technology Acceptance Model and the Unified Theory of Acceptance (TAM) [16] and Use of Technology (UTAUT) [70]. Trust has been included in technology adoption research studies in various contexts such as e-government, e-commerce, or driverless cars [31, 37, 62]. In this study context, trust is defined as beliefs an individual holds about the desired attributes of a technology (Microsoft Teams) $[23,43]$. The concept of trust originally stems from psychology research in association with human-tohuman trust. Therefore, interpersonal trust is the outcome of the social judgment that the other person will perform as expected in risky situations [41]. McKnight et al. [45] concluded that trust is derived on the basis of the individual's beliefs about the benevolence, competence, honesty, and predictability of another person [45]. On this basis, they define trust in technology as an individual's beliefs about the helpfulness, functionality, and reliability of a technology [43]. Helpfulness refers to the belief that the technology offers useful and immediate help for the user. Functionality denotes the belief about the technology's capability or features to be able to do what the user needs to be done. Reliability is defined as the belief about the technology's consistent behavior which can be forecasted by the user [43]. This paper refers to this trust definition with system-like trust [33].

Lankton et al. [33] however also considered that people tend to also appraise human-like attributes to technology and, therefore, extended trust in technology theory. They empirically tested and showed that there is a difference between human-like trust and systemlike trust in technologies. They define that human-like trusting beliefs consist of the beliefs in integrity, ability and benevolence. Integrity refers to the trustor's belief about the trustee's principles, they adhere to, and which the trustor also supports [41]. Competence is the trustor's belief that the trustee is able to do what the trustor expects them to do [45]. And benevolence is associated with the belief that the trustee intends to do 
good to the trustor [33, 41]. Lankton et al. [33] argued that there are also technology characteristics, which make a technology seem more human-like. For example, the concept of social presence posits that the technology's characteristics impact the perception as to how a technology is perceived as sociable, warm and personal. These perceptions are built on the user's experience as being psychologically present [24]. In this study, Microsoft Teams fulfills social presence in that it offers features to instantly chat, call, or even do a video-conference. One can also open teams and work together on projects, which simulates a physically present work environment. All of these features are proven to enhance the perception of social presence in technologies [14, 51, 73]. Therefore, human-like trust in addition to system-like trust is integrated into the proposed research model in order to capture the holistic concept of the impact of trust on technostress creators.

It needs to be noted that in this study, trust is conceptualized as uni-dimensional, meaning that trust and distrust are bipolar opposites of the applied scale [39] in order to simplify the research model for the scope of this article.

\section{Hypotheses development}

According to studies, trust positively impacts the perception of usefulness, enjoyment, and technology adoption [33]. Combining these findings with technostress research $[69,76]$, that perceived usefulness and perceived ease of use are positive predictors of techno-eustress by reducing the perception of negative hindrance technostressors and increasing the perception of positive challenge technostressors, it is inferred that trust in technology is negatively related to the appraisal of technostress creators, which are defined as hindrance stressors in this study.

H1: System-like trust is negatively related to the appraisal of technostress creators.

It needs to be noted that the concept of system-like trust in technology is also derived from definitions of trust between people. Therefore, the three elements of system-like trust and human-like trust are congruent in their meanings. However, Lankton et al. [33] found that users perceive differences in humanness between technologies, which influences their trust in technologies. Their results show that the more humanlike a technology is perceived, the stronger is the impact of human-like trusting beliefs. Similarly, the more system-like the technology is perceived, the stronger is the influence of system-like trusting beliefs [33]. Since Microsoft Teams incorporates both systemlike and human-like attributes, it is argued that also human-like trust impacts the appraisal of technostress creators.

H2: Human-like trust is negatively related to the appraisal of technostress creators.

Research on technostress already showed that certain technology characteristics increase the level of perceived distress and therefore also decrease the level of perceived eustress. Since technostress creators are conceptualized according to Ragu-Nathan et al. [52], these stressors will be positively related to perceived distress and negatively related to perceived eustress.

H3: Technostress creators are negatively related to perceived eustress.

H4: Technostress creators are positively related to perceived distress.

Studies already investigated the relationship between technostress creators, perceived stress and job satisfaction [52, 61, 68, 69]. Accordingly, this paper joins the body of knowledge and verifies with this study the results.

H5: Perceived eustress is positively related to job satisfaction.

H6: Perceived distress is negatively related to job satisfaction.

Figure 2 summarizes and illustrates the derived research model with the proposed effects in parentheses.

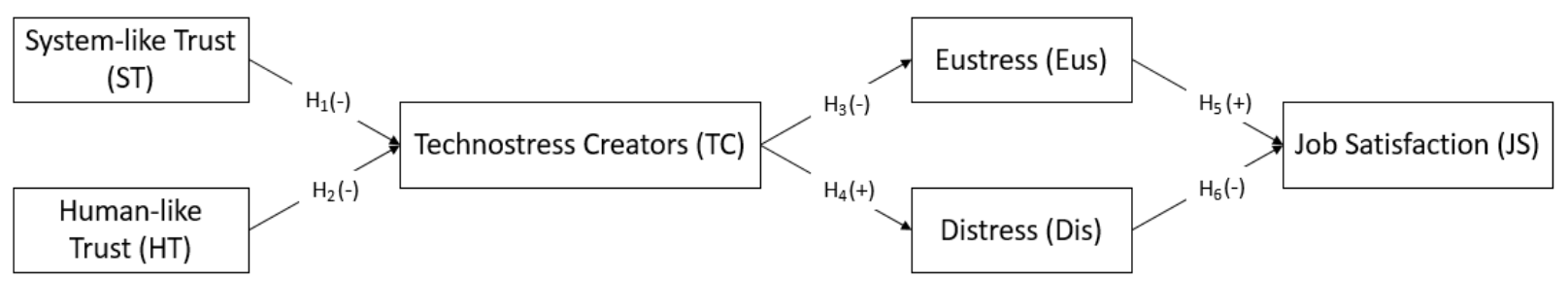

Figure 2. Research model 


\section{Method}

The objective of this paper is to clarify the effects of trust on technostress creators in work environments. In order to empirically test the proposed research model, a field study was conducted for data collection. Structural equation modelling is used for the statistical analysis.

\subsection{Data collection}

The data were collected with an online survey. The target population for this study was not limited to any specific profession as it is intended to analyze and understand the impact of trust on technostress creators in general work settings. However, the sample was controlled for the daily usage of Microsoft Teams at work. A total of 210 respondents were acquired who meet the screening criteria of using Microsoft Teams for work for at least one hour daily and who fully filled the questionnaire.

\subsection{Measures}

Existing validated scales were adapted in order to measure the constructs with regard to Microsoft Teams use and experience. The reflective items for systemlike trust and human-like trust are taken from Lankton et al. [33]. The measures for the technostress creators techno-overload, techno-invasion, techno-complexity, techno- uncertainty, and techno-insecurity, as well as the items for job satisfaction were taken from RaguNathan et al. [52]. The reflective items for perceived eustress and perceived distress were adapted from Branson et al. [4] and O'Sullivan [46]. For the validation of all constructs, a confirmatory factor analysis was performed.

All items are measured on a seven point LikertScale, where 1 stands for "I do not agree at all" and 7 indicates "I totally agree". For example, the technostress creator techno-complexity has a high score if the complexity of Microsoft Teams is perceived to be high and negative by the respondents, whereas low points rather indicate that Microsoft Teams is not complex but rather easy to use.

In addition, control variables were collected, such as gender, age, work experience in years, average daily usage time of Microsoft Teams for work.

\section{Data analysis}

For data analysis and testing the proposed hypotheses, partial least squares structural equation modelling (PLS SEM) was applied. PLS SEM has the advantage that it does not assume any specific distribution and is also valid for smaller sample sizes $[11,12]$.

In total, 210 fully filled questionnaires were received, which meet the set requirements of using Microsoft Teams on a daily basis for work (see section 4.1). Out of the 210 individuals, $62.9 \%$ were female and $37.1 \%$ were male $(0 \%$ other $)$. All of the participants had at least one year of work experience and over $90 \%$ work from home for at least $20 \%$ of their time.

\subsection{Measurement model}

The measured items are indicators for the latent unobservable variables that represent the constructs. Therefore, the reliability and validity of the constructed measures were tested [54]. Table 1 demonstrates that the average variance extracted (AVE) for all constructs exceeds the necessary threshold of 0.5 [20] confirming the validity of the constructs. To ensure the reliability of the measures, the composite reliability and Cronbach's Alpha were calculated. All values exceed the required threshold of 0.6 and, therefore, confirm the reliability of our constructs measurement (Table 1).

Table 1. Validity and reliability statistics of the measurement model

\begin{tabular}{|l|c|c|c|}
\cline { 2 - 4 } \multicolumn{1}{c|}{} & $\begin{array}{c}\text { Average } \\
\text { Variance } \\
\text { Extracted }\end{array}$ & $\begin{array}{c}\text { Cronbach's } \\
\text { Alpha }\end{array}$ & $\begin{array}{c}\text { Composite } \\
\text { Reliability }\end{array}$ \\
\hline Human-like Trust & 0.705 & 0.941 & 0.950 \\
\hline $\begin{array}{l}\text { Technom-like Trust } \\
\text { Creators }\end{array}$ & 0.611 & 0.922 & 0.934 \\
\hline Eustress & 0.662 & 0.959 & 0.964 \\
\hline Distress & 0.634 & 0.936 & 0.945 \\
\hline Job satisfaction & 0.887 & 0.958 & 0.969 \\
\hline
\end{tabular}

Table 2. Fornell-Larcker criterion test results

\begin{tabular}{lcccccc}
\hline & TC & Dis & Eus & HT & JS & ST \\
\hline TC & $\mathbf{0 . 8 2 8}$ & & & & & \\
Dis & 0.683 & $\mathbf{0 . 9 4 2}$ & & & & \\
Eus & -0.603 & -0.590 & $\mathbf{0 . 7 9 7}$ & & & \\
HT & -0.524 & -0.414 & 0.465 & $\mathbf{0 . 8 3 9}$ & & \\
JS & -0.449 & -0.516 & 0.633 & 0.437 & $\mathbf{0 . 9 3 4}$ & \\
ST & -0.496 & -0.417 & 0.463 & 0.731 & 0.425 & $\mathbf{0 . 7 8 2}$ \\
\hline
\end{tabular}

Table 2 reports the Fornell-Larcker criterion test results, which measure the discriminant validity. All measures meet the required criteria [20]. In addition, it was also controlled for discriminant validity with the HTMT criterion (Table 3). The values are below 0.85 indicating discriminant validity $[25,26]$. 
Table 3. HTMT criterion test results

\begin{tabular}{lccccc}
\hline & TC & Dis & Eus & HT & JS \\
\hline Dis & 0.708 & & & & \\
Eus & 0.622 & 0.610 & & & \\
HT & 0.525 & 0.422 & 0.489 & & \\
JS & 0.471 & 0.544 & 0.673 & 0.462 & \\
ST & 0.493 & 0.427 & 0.502 & 0.780 & 0.459 \\
\hline
\end{tabular}

\subsection{Structural model}

The structural model was tested for multicollinearity based on the variance inflation factors (VIF). As shown in Table 4, all VIF values are below the threshold of 3 . This indicates no multi-collinearity between the constructs $[30,55]$.

Table 4. Variance inflation factors

\begin{tabular}{lcccc}
\hline & TC & Dis & Eus & JS \\
\hline TC & & 1.000 & 1.000 & \\
Dis & & & & 1.534 \\
Eus & & & & 1.534 \\
HT & 2.147 & & & \\
ST & 2.147 & & & \\
\hline
\end{tabular}

The total effects are calculated based on PLS SEM and tested for significance. Figure 3 shows the model with its path coefficients and significance levels for the postulated hypotheses.

The control variables gender, age, amount of MS Teams usage for work, and work experience show no significant effects on job satisfaction. However, introducing the control variables amount of MS Teams usage for work and work experience to technostress creators, they show having a significant impact. The variable amount of MS Teams usage for work shows a significant effect at 0.001 level with a path coefficient of 0.231 . The variable work experience shows a significant effect at 0.05 level with a path coefficient of -0.151 . Including both variables in the model, increases
$\mathrm{R}^{2}$ of technostress creators from $30.2 \%$ to $36.4 \%$.

\section{Discussion}

The analysis of the proposed structural model shows that all of our hypothesized relationships are supported by our quantitative study. $30.2 \%$ of the variance of the appraisal of technostress creators is explained by the proposed model in that system-like trust and human-like trust negatively contribute to the appraisal of technostress creators $(\mathrm{H} 1$ and $\mathrm{H} 2)$. It is interesting to see that system-like trust has a smaller effect on technostress creators (H1) than human-like trust (H2). These results can be explained the following way: users tend to attribute more human-like characteristics to Microsoft Teams than system-like attributes. This is because of the software's features which emphasize the technology's social presence (e.g. chat function, teams, video-conferencing, exchange of emojis) [33].

Furthermore, the results provide support for the impact of technostress creators on perceived eustress and distress which is in accordance to prior studies [8, 52, 68, 76, 77]. Technostress creators, which are conceptualized as hindrance stressors evidently lead to an increased distress level (H4) and decrease the perception of eustress (H3). These stress perceptions, in turn, affect the employee's job satisfaction. In line with prior investigations, eustress positively impacts jobs satisfaction $[9,50]$ and distress decreases job satisfaction $[52,68]$. However, the effect of distress on job satisfaction is considerably lower than the impact of eustress on job satisfaction. This result may stem from the nature of the conceptualization of job satisfaction. Job satisfaction is conceptualized and framed in a positive way as opposed to constructs such as job burnout or job dissatisfaction.

To conclude, the results support the proposed research model (Figure 3) and the analysis provides evidence that both system-like trust and human-like trust in technology are negatively impacting the appraisal of technostress creators. These findings also

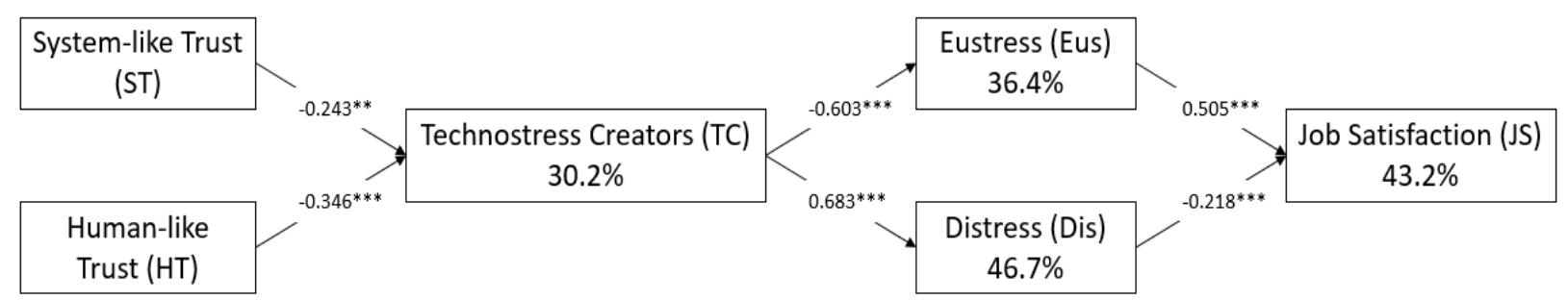

Path significances: ${ }^{* * *} p<0.001 ;{ }^{* *} p<0.01 ;{ }^{*} p<0.05$

Percentages indicate the percentage of variance explained

Figure 3. Results of the research model 
have practical implications. Knowing that technostress creators positively impact perceived distress and negatively impact perceived eustress, it is of interest to reduce the perception of technostress creators in order to reduce distress and mitigate the negative impact on eustress. With the knowledge that trust in technologies affects the appraisal of technostress creators, employers as well as employees should focus on building trust in the technologies they use. There are already studies, which examined the determinants of trust in technologies (e.g. knowledge, attitude, perceived behavioral control) [27, 65], however, I suggest to theoretically and empirically test these antecedents in the context of technostress in future research.

In addition, this study contributes to academic knowledge and technostress literature as this study theoretically derives and empirically proves that trust in technology significantly impacts the appraisal of technostress creators, which in turn affects perceived stress.

\section{Conclusions and outlook}

The research objective of this study was to examine the role and impact of trust in the technostress process. In order to test the derived hypotheses, data were collected from 210 employees on their system-like trust and human-like trust in Microsoft Teams and their appraisal of Microsoft Teams as technostress creator. In particular, it is found that both, system-like trust and human-like trust, negatively impact the appraisal of technostress creators, which in turn induces perceived distress and decreases perceived eustress.

Although this study is a fruitful extension of technostress research, it also comes along with some limitations. First, this study used Microsoft Teams as technology which stands for technostress creators. As Microsoft Teams offers both system-like and humanlike advantages as a technology, there might be other results when conducting the same study with a different technology (e.g. Microsoft Access vs. Facebook [33]). Therefore, I suggest further studies focusing on different technologies. Second, I accounted for trust and distrust with a uni-dimensional scale as being bipolar opposites on the same scale [39]. However, I propose to disentangle trust into two separate constructs and test their impact on the appraisal of technostress creators in future research. In addition, the study focused on technology use in a work-related context. Future research can investigate trust in the technostress process in private settings.

\section{References}

[1] Ayyagari, R., V. Grover, and R. Purvis, "Technostress: Technological antecedents and implications", MIS Quarterly: Management Information Systems 35(4), 2011, pp. 831-858.

[2] Barber, L.K., and A.M. Santuzzi, "Please respond ASAP: Workplace telepressure and employee recovery.", Journal of Occupational Health Psychology 20(2), 2015, pp. 172-189.

[3] Bichteler, J., "Human Aspects of High Tech in Special Libraries.”, Special Libraries 77(3), 1986, pp. 121-28.

[4] Branson, V., M.J. Dry, E. Palmer, and D. Turnbull, "The Adolescent Distress-Eustress Scale: Development and Validation", SAGE Open 9(3), 2019, pp.

215824401986580.

[5] Brod, C., "Managing technostress: optimizing the use of computer technology.", The Personnel journal 61(10), 1982, pp. 753-7.

[6] Brod, C., Technostress: the human cost of the computer revolution, Addison-Wesley, Reading, 1984.

[7] Brown, R., J. Duck, and N. Jimmieson, "E-mail in the workplace: The role of stress appraisals and normative response pressure in the relationship between e-mail stressors and employee strain.", International Journal of Stress Management 21(4), 2014, pp. 325-347.

[8] Califf, C.B., S. Sarker, and S. Sarker, "The Bright and Dark Sides of Technostress: A Mixed-Methods Study Involving Healthcare IT.", MIS Quarterly 44(2), 2020, pp. 809-856.

[9] Cavanaugh, M.A., W.R. Boswell, M. V. Roehling, and J.W. Boudreau, "An empirical examination of selfreported work stress among U.S. managers", Journal of Applied Psychology 85(1), 2000, pp. 65-74.

[10] Champion, S., “Technostress: Technology's Toll.", School Library Journal 35(3), 1988, pp. 48-51. [11] Chin, W.W., "The partial least squares approach for structural equation modeling", In Modern Methods for Business Research. Erlbaum Associates, London, UK, 1998, 295-336.

[12] Chin, W.W., and P.R. Newsted, "Structural equation modeling analysis with small samples using partial least squares", In Statistical Methods for Small Sample Research. Hoyle, Thousand Oaks, 1999, 307342.

[13] Çoklar, A.N., and Y.L. Şahin, "Technostress levels of social network users based on ICTS in Turkey", European Journal of Social Sciences 23(2), 2011, pp. 171-182.

[14] Cyr, D., M. Head, H. Larios, and B. Pan, "Exploring human images in website design: A multimethod approach", MIS Quarterly: Management Information Systems 33(3), 2009, pp. 539-566. 
[15] D’Arcy, J., T. Herath, and M.K. Shoss, "Understanding Employee Responses to Stressful Information Security Requirements: A Coping Perspective", Journal of Management Information Systems 31(2), 2014, pp. 285-318.

[16] Davis, F.D., "Perceived Usefulness, Perceived Ease of Use, and User Acceptance of Information Technology", MIS Quarterly 13(3), 1989, pp. 319-339. [17] Day, A., S. Paquet, N. Scott, and L. Hambley, "Perceived information and communication technology (ICT) demands on employee outcomes: The moderating effect of organizational ICT support.", Journal of Occupational Health Psychology 17(4), 2012, pp. 473-491.

[18] Folkman, S., "Positive psychological states and coping with severe stress", Social Science and Medicine 45(8), 1997, pp. 1207-1221.

[19] Folkman, S., R.S. Lazarus, C. Dunkel-Schetter, A. DeLongis, and R.J. Gruen, "Dynamics of a stressful encounter: Cognitive appraisal, coping, and encounter outcomes.", Journal of Personality and Social Psychology 50(5), 1986, pp. 992-1003.

[20] Fornell, C., and D.F. Larcker, "Evaluating Structural Equation Models with Unobservable Variables and Measurement Error", Journal of Marketing Research 18(1), 1981, pp. 39-50. [21] Fuglseth, A.M., and Ø. Søreb $\varnothing$, "The effects of technostress within the context of employee use of ICT", Computers in Human Behavior 40, 2014, pp. 161-170.

[22] Galluch, P., V. Grover, and J. Thatcher, "Interrupting the Workplace: Examining Stressors in an Information Technology Context", Journal of the Association for Information Systems 16(1), 2015, pp. $1-47$.

[23] Gefen, D., I. Benbasat, and P.A. Pavlou, "A research agenda for trust in online environments", Journal of Management Information Systems 24(4), 2008, pp. 275-286.

[24] Gunawardena, C.N., and C.N. Gunawardena, "Social Presence Theory and Implications for Interaction and Collaborative...", International Journal of Educational Telecommunications 1(2), 1995, pp. 147-166.

[25] Hair, J.F., G.T.M. Hult, C.M. Ringle, and M. Sarstedt, A Primer on Partial Least Squares Structural Equation Modeling, Sage, Thousand Oaks, 2017. [26] Henseler, J., C.M. Ringle, and M. Sarstedt, "A new criterion for assessing discriminant validity in variance-based structural equation modeling", Journal of the Academy of Marketing Science 43(1), 2015, pp. 115-135.

[27] Ho, S.M., M. Ocasio-Velázquez, and C. Booth, "Trust or consequences? Causal effects of perceived risk and subjective norms on cloud technology adoption", Computers and Security 70, 2017, pp. 581595.

[28] Hsiao, K.-L., Y. Shu, and T.-C. Huang,

"Exploring the effect of compulsive social app usage on technostress and academic performance:

Perspectives from personality traits", Telematics and Informatics 34(2), 2017, pp. 679-690.

[29] Hwang, I., and O. Cha, "Examining technostress creators and role stress as potential threats to employees' information security compliance", Computers in Human Behavior 81, 2018, pp. 282-293. [30] Jagpal, H.S., "Multicollinearity in Structural Equation Models with Unobservable Variables", Journal of Marketing Research 19(4), 1982, pp. 431439.

[31] Kaur, K., and G. Rampersad, "Trust in driverless cars: Investigating key factors influencing the adoption of driverless cars", Journal of Engineering and Technology Management - JET-M 48, 2018, pp. 87-96. [32] Krishnan, S., "Personality and espoused cultural differences in technostress creators", Computers in Human Behavior 66, 2017, pp. 154-167.

[33] Lankton, N.K., D. Harrison Mcknight, and J. Tripp, "Technology, humanness, and trust: Rethinking trust in technology", Journal of the Association for Information Systems 16(10), 2015, pp. 880-918. [34] Lazarus, R.S., Psychological stress and the coping process, McGraw-Hill, New York, NY, USA, 1966. [35] Lazarus, R.S., and S. Folkman, Stress, appraisal, and coping, Springer publishing company, New York, NY, USA, 1984.

[36] Lazarus, R.S., and S. Folkman, "Cognitive Theories of Stress and the Issue of Circularity", In Dynamics of Stress. Springer US, Boston, MA, 1986, 63-80.

[37] Lee, J., H.J. Kim, and M.J. Ahn, “The willingness of e-Government service adoption by business users:

The role of offline service quality and trust in technology", Government Information Quarterly 28(2), 2011, pp. 222-230.

[38] Lee, Y.-K., C.-T. Chang, Y. Lin, and Z.-H. Cheng, "The dark side of smartphone usage: Psychological traits, compulsive behavior and technostress",

Computers in Human Behavior 31, 2014, pp. 373-383. [39] Lewicki, R.J., E.C. Tomlinson, and N. Gillespie, "Models of Interpersonal Trust Development: Theoretical Approaches, Empirical Evidence, and Future Directions", Journal of Management 32(6), 2006, pp. 991-1022.

[40] Maier, C., S. Laumer, C. Weinert, and T. Weitzel, "The effects of technostress and switching stress on discontinued use of social networking services: a study of Facebook use", Information Systems Journal 25(3), 2015, pp. 275-308.

[41] Mayer, R.C., J.H. Davis, and F.D. Schoorman, 
"An Integrative Model of Organizational Trust", Academy of Management Review 20(3), 1995, pp. 709734.

[42] McGowan, J., D. Gardner, and R. Fletcher, "Positive and Negative Affective Outcomes of Occupational Stress", New Zealand Journal of Psychology 35(2), 2006, pp. 92-98.

[43] Mcknight, D.H., M. Carter, J.B. Thatcher, and P.F. Clay, "Trust in a specific technology: An investigation of its components and measures", ACM Transactions on Management Information Systems 2(2), 2011, pp. 1-25.

[44] McKnight, D.H., and N.L. Chervany, "What trust means in e-commerce customer relationships: An interdisciplinary conceptual typology", International Journal of Electronic Commerce 6(2), 2001, pp. 3559.

[45] McKnight, D.H., V. Choudhury, and C. Kacmar, "Developing and validating trust measures for ecommerce: An integrative typology", Information Systems Research 13(3), 2002, pp. 334-359.

[46] O'Sullivan, G., "The Relationship between Hope, Eustress, Self-Efficacy, and Life Satisfaction among Undergraduates", Social Indicators Research 101(1), 2011, pp. 155-172.

[47] Ortiz de Guinea, A., "A pragmatic multi-method investigation of discrepant technological events: Coping, attributions, and 'accidental' learning",

Information \& Management 53(6), 2016, pp. 787-802. [48] Pavlou, P.A., "Consumer acceptance of electronic commerce: Integrating trust and risk with the technology acceptance model", International Journal of Electronic Commerce 7(3), 2003, pp. 101-134. [49] Pflügner, K., C. Maier, J. Mattke, and T. Weitzel, "Personality Profiles that Put Users at Risk of Perceiving Technostress: A Qualitative Comparative Analysis with the Big Five Personality Traits", Business and Information Systems Engineering 63(4), 2021, pp. 389-402.

[50] Podsakoff, N.P., J.A. Lepine, and M.A. Lepine, "Differential challenge stressor-hindrance stressor relationships with job attitudes, turnover intentions, turnover, and withdrawal behavior: A meta-analysis", Journal of Applied Psychology 92(2), 2007, pp. 438454.

[51] Qiu, L., and I. Benbasat, "Evaluating

anthropomorphic product recommendation agents: A social relationship perspective to designing information systems", Journal of Management Information Systems 25(4), 2008, pp. 145-182.

[52] Ragu-Nathan, T.S., M. Tarafdar, B.S. Ragu-

Nathan, and Q. Tu, "The Consequences of

Technostress for End Users in Organizations:

Conceptual Development and Empirical Validation", Information Systems Research 19(4), 2008, pp. 417-
433.

[53] Rodríguez, I., M.W. Kozusznik, and J.M. Peiró, "Development and Validation of the Valencia Eustress-Distress Appraisal Scale", International Journal of Stress Management, 2013.

[54] Roldán, J.L., and M.J. Sánchez-Franco, "Variance-based structural equation modeling: Guidelines for using partial least squares in information systems research", In Research Methodologies, Innovations and Philosophies in Software Systems Engineering and Information Systems. IGI Global, 2012, 193-221.

[55] Salmerón Gómez, R., J. García Pérez, M.D.M. López Martín, and C.G. García, "Collinearity diagnostic applied in ridge estimation through the variance inflation factor", Journal of Applied Statistics 43(10), 2016, pp. 1831-1849.

[56] Selye, H., "Stress without Distress BT Psychopathology of Human Adaptation", In G. Serban, ed., Serban G. (eds). Psychopathology of Human Adaptation. Springer US, 1976, 137-146.

[57] Sherman, E., A. Mathur, and R.B. Smith, "Store environment and consumer purchase behavior: Mediating role of consumer emotions", Psychology \& Marketing 14(4), 1997, pp. 361-378.

[58] Shu, Q., Q. Tu, and K. Wang, "The Impact of Computer Self-Efficacy and Technology Dependence on Computer-Related Technostress: A Social Cognitive Theory Perspective", International Journal of Human-Computer Interaction 27(10), 2011, pp. 923-939.

[59] Soucek, R., and K. Moser, "Coping with information overload in email communication: Evaluation of a training intervention", Computers in Human Behavior 26(6), 2010, pp. 1458-1466.

[60] Sprigg, C.A., and P.R. Jackson, "Call centers as lean service environments: Job-related strain and the mediating role of work design.", Journal of Occupational Health Psychology 11(2), 2006, pp. 197212.

[61] Srivastava, S.C., S. Chandra, and A. Shirish, "Technostress creators and job outcomes: theorising the moderating influence of personality traits", Information Systems Journal 25(4), 2015, pp. 355-401. [62] Srivastava, S.C., S. Chandra, and Y.-L. Theng, "Evaluating the Role of Trust in Consumer Adoption of Mobile Payment Systems: An Empirical Analysis", Communications of the Association for Information Systems 27, 2010, pp. 561-588.

[63] Sykes, T.A., "Support Structures and Their Impacts on Employee Outcomes: A Longitudinal Field Study of an Enterprise System Implementation", MIS Quarterly 39(2), 2015, pp. 437-495.

[64] Tams, S., K. Hill, A. Guinea, J. Thatcher, and V. Grover, "NeuroIS - Alternative or Complement to 
Existing Methods? Illustrating the Holistic Effects of Neuroscience and Self-Reported Data in the Context of Technostress Research", Journal of the Association for Information Systems 15(10), 2014, pp. 723-753.

[65] Tams, S., J.B. Thatcher, and K. Craig, "How and why trust matters in post-adoptive usage: The mediating roles of internal and external self-efficacy", Journal of Strategic Information Systems 27(2), 2018, pp. 170-190.

[66] Tarafdar, M., C.L. Cooper, and J. Stich, "The technostress trifecta - techno eustress, techno distress and design: Theoretical directions and an agenda for research", Information Systems Journal 29(1), 2019, pp. 6-42.

[67] Tarafdar, M., E.B. Pullins, and T.S. Ragu-Nathan, "Technostress: negative effect on performance and possible mitigations", Information Systems Journal 25(2), 2015, pp. 103-132.

[68] Tarafdar, M., Q. Tu, B.S. Ragu-Nathan, and T.S. Ragu-Nathan, "The Impact of Technostress on Role Stress and Productivity", Journal of Management Information Systems 24(1), 2007, pp. 301-328. [69] Tarafdar, M., Q. Tu, and T.S. Ragu-Nathan, "Impact of Technostress on End-User Satisfaction and Performance", Journal of Management Information Systems 27(3), 2010, pp. 303-334.

[70] Venkatesh, V., M.G. Morris, G.B. Davis, and F.D. Davis, "User acceptance of information technology:

Toward a unified view", MIS Quarterly: Management Information Systems 27(3), 2003, pp. 425-478.

[71] Venkatesh, V., J.Y.L. Thong, and X. Xu, "Consumer acceptance and use of information technology: Extending the unified theory of acceptance and use of technology", MIS Quarterly: Management Information Systems 36(1), 2012, pp. 157-178.

[72] Wang, T.-H., "Web-based dynamic assessment: Taking assessment as teaching and learning strategy for improving students' e-Learning effectiveness", Computers \& Education 54(4), 2010, pp. 1157-1166. [73] Wang, W., and I. Benbasat, "Recommendation agents for electronic commerce: Effects of explanation facilities on trusting beliefs", Journal of Management Information Systems 23(4), 2007, pp. 217-246.

[74] Zhang, S., L. Zhao, Y. Lu, and J. Yang, "Do you get tired of socializing? An empirical explanation of discontinuous usage behaviour in social network services", Information \& Management 53(7), 2016, pp. 904-914.

[75] Zhao, X., Q. Xia, and W. Huang, "Impact of technostress on productivity from the theoretical perspective of appraisal and coping processes", Information and Management, 2020.

[76] Zielonka, J.T., and F. Rothlauf, "Techno-Eustress: The Impact of Perceived Usefulness and Perceived Ease of Use on the Perception of Work-Related
Stressors", Proceedings of the 54th Hawaii International Conference on System Sciences, Hawaii International Conference on System Sciences (2021). [77] Zielonka, J.T., and F. Rothlauf, "Challenge Accepted: On the Juxtaposed Effect of the Appraisal of Social Media as Challenge and Hindrance Stressors on the Perception of Eustress and Distress", PACIS 2021 Proceedings, 2021. 